\title{
Residual life estimation of structural beam using experimental and numerical modal analysis methods
}

Gandam Anand SIVA, Shinagam RAMAKRISHNA

DOI: 10.30464/jmee.2020.4.2.135

Cite this article as:

Siva G. A., Ramakrishna S. Residual life estimation of structural beam using experimental and numerical modal analysis methods. Journal of Mechanical and Energy Engineering, Vol. 4(44), No. 2, 2020, pp. 135-146.

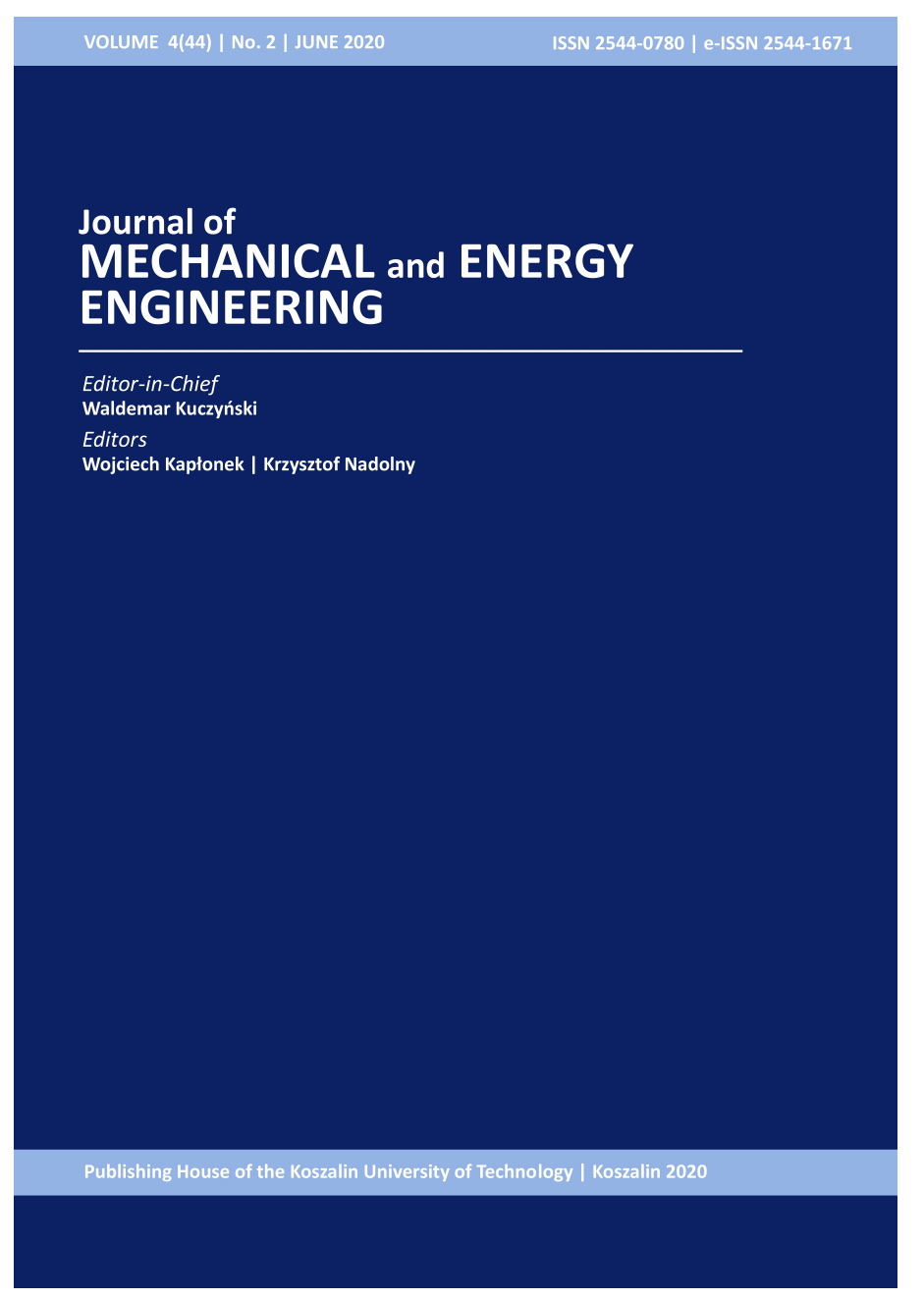

Journal of Mechanical and Energy Engineering

Website: jmee.tu.koszalin.pl

ISSN (Print): 2544-0780

ISSN (Online): 2544-1671

Volume: 4(44)

Number: 2

Year: 2020

Pages: $135-146$

Article Info:

Received 3 June 2020

Accepted 10 July 2020

Open Access

This article is distributed under the terms of the Creative Commons Attribution 4.0 (CC BY 4.0) International License (http://creativecommons.org/licenses/by/4.0/), which permits unrestricted use, distribution, and reproduction in any medium, provided you give appropriate credit to the original author(s) and the source, provide a link to the Creative Commons license, and indicate if changes were made. 


\title{
RESIDUAL LIFE ESTIMATION OF STRUCTURAL BEAM USING EXPERIMENTAL AND NUMERICAL MODAL ANALYSIS METHODS
}

\author{
Gandam Anand SIVA ${ }^{1 *}$, Shinagam RAMAKRISHNA ${ }^{2}$ \\ ${ }^{1 *}$ Assistant Professor, Department of Mechanical Engineering, GVP-Satya Institute of Technology \\ and Management, Vizianagaram, India, e-mail: gandamanandsiva@gmail.com \\ ${ }^{2}$ Associate Professor, Department of Mechanical Engineering, Gayatri Vidya Parishad College of Engineering \\ (Autonomous), Visakhapatnam-530048, India
}

(Received 3 June 2020, Accepted 10 July 2020)

\begin{abstract}
A structural beam is a common element in many mechanical structures such as ship propeller shaft, crane boom, and aircraft wings. In the present paper experimental and numerical modal analysis are carried out for estimating the damage, geometric location of the damage, severity of damage and residual life of structural beam to prevent unexpected failures of mechanical structures. Experimental and numerical modal analysis results for healthy and cracked beam are compared for validation of numerical methodology used in the present paper. Experimental modal analysis is performed on both healthy and cracked beam with the help of impact hammer, acceleration sensor and FFT (Fast Fourier Transformer) analyzer associated with EDM (Engineering Data Management) software. Modal tests are conducted using impact method on selected locations of the entire healthy and cracked beam to find the first three natural frequencies, which are used to detect the presence of damage and geometric location of the damage. Three parametric studies are carried out to know the effect of crack depth, crack location and crack orientation on the natural frequencies of the cracked beam. Finally, the residual life of a healthy and cracked beam was estimated using Basiquin's equation and finite element analysis software called ANSYS 18.1.
\end{abstract}

Keywords: structural beam, residual life estimation, FFT analyzer, damage detection, crack location, the natural frequencies

\section{INTRODUCTION}

During the last two decades, a lot of attention was given on structural health monitoring to prevent premature failure of the mechanical structures. Experimental modal analysis based structural health monitoring is used as a tool for estimating the damage detection, geometric location of the damage, severity of damage and remaining life (Residual life) of the structure. Structural health monitoring is a process of implementing damage identification and characterization strategy for engineering structures $[4,5,6]$. There are different non-destructive testing methods such as ultrasonic testing, X-ray, magnetic particle, liquid penetrant technique, eddy current, and acoustic emission are available for earlier damage detection in structures [7]. But they are very expensive, time-consuming and some of them are difficult to implement for complex structures such as air craft's, railway tracks, long columns and long pipelines in power plants. Experimental modal analysis has become a standard procedure for identification of damage, location, and its severity after the existence of damage in many industries[8].

So far a lot of research has been performed to estimate the residual life of the beam. Rytter[2] presented four steps for health monitoring of a system.

1. Step1: Identification of damage presents in the structure.

2. Step2: Detecting the geometric location of the structure damage.

3. Step3: Quantification of severity of the damage.

4. Step4: Calculating the residual life of the structure. 
But no work has done to implement all these steps on real-time systems. Our research aims at implementing all these steps in a structural beam.

\section{EXPERIMENTAL MODAL ANALYSIS ON HEALTHY AND CRACKED BEAM}

Experimental modal analysis indicates the variation of natural frequencies, mode shapes, and modal damping with a physical change in the structures. Damage present in the structures can be identified by variation of natural frequencies between healthy and cracked beam $[9,10,11]$. The change of natural frequency occurs in healthy and cracked beam because of the variation of stiffness in healthy and cracked beam. For this purpose, experimental modal analysis was performed on healthy and cracked beam for identification of damage present in the structure. A structural beam of dimensions $500 \times 50 \times 6 \mathrm{~mm}$ is considered for experimental modal analysis. Table 1 shows the material properties of a structural beam. A transverse crack of width and depth is $1.25 \mathrm{~mm}$ and $2 \mathrm{~mm}$ respectively is made at a distance of $150 \mathrm{~mm}$ from the fixed end of the beam. Figure 1 and Figure 2 shows line diagrams of healthy and cracked beam respectively. An experimental modal analysis was performed on a healthy and cracked beam with the help of FFT analyzer (Fast Fourier Transformer), impact hammer and accelerometer. The frequency range is selected from 0 to $1440 \mathrm{~Hz}$ for all measurements on healthy and cracked beam. The sensitivity of the impact hammer is $10 \mathrm{mv} / \mathrm{g}$ and accelerometer sensor is 96 $\mathrm{mv} / \mathrm{g}$. Figure 3 shows the image of instruments used for experimental modal analysis. Modal frequencies of healthy and cracked beam obtained from the experimental modal analysis are compared to detect the damage present in the structure. Figure 4 shows the image of experimental modal analysis on a healthy and cracked beam. The frequency response spectrum obtained from the experimental modal analysis for a healthy beam is shown in Figure 5. The first, second and third natural frequencies of a healthy beam obtained from the experimental modal analysis are $20.25 \mathrm{~Hz}, 127.5 \mathrm{~Hz}$ and $340 \mathrm{~Hz}$ respectively. Figure 6 indicates the frequency response spectrum obtained from experimental modal analysis on cracked beam. Figure 6 clearly indicates the first, second and third natural frequencies of cracked beam obtained from experimental modal analysis are $19.53 \mathrm{~Hz}, 120.31$ $\mathrm{Hz}$ and $336.03 \mathrm{~Hz}$ respectively. Table 2 indicates the experimental modal analysis results of the healthy and cracked beam.
Tab. 1.Structural beam material properties

\begin{tabular}{lc}
\hline Parameter & Value \\
\hline Specimen commercial name & $\begin{array}{c}\text { IS 2062 Mild } \\
\text { Steel }\end{array}$ \\
\hline Modulus of elasticity $(\mathrm{E})$ in GPa & 200 \\
\hline Density $(\rho)$ in $\mathrm{kg} / \mathrm{m}^{3}$ & 7850 \\
\hline Poisons ratio $[\mu]$ & 0.3 \\
\hline
\end{tabular}

Tab. 2.Experimental modal analysis results of healthy and cracked beam

\begin{tabular}{rcc}
\hline \multirow{2}{*}{ Mode } & \multicolumn{2}{c}{ Natural frequencies $[\mathrm{Hz}]$} \\
\cline { 2 - 3 } & Healthy beam & Cracked beam \\
\hline 1 & 20.25 & 19.53 \\
\hline 2 & 127.5 & 120.31 \\
\hline 3 & 340 & 336.03 \\
\hline
\end{tabular}

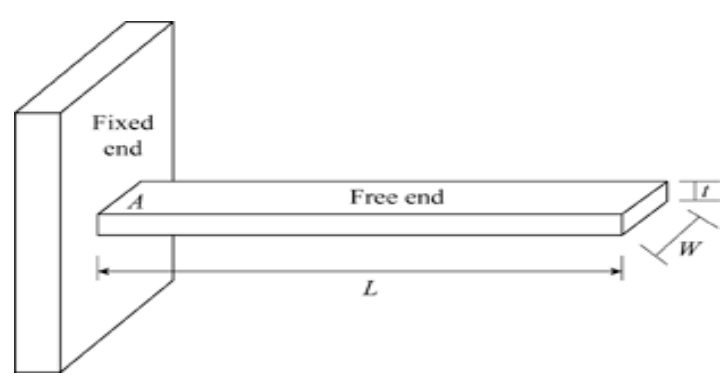

Fig. 1.Line diagram of healthy beam

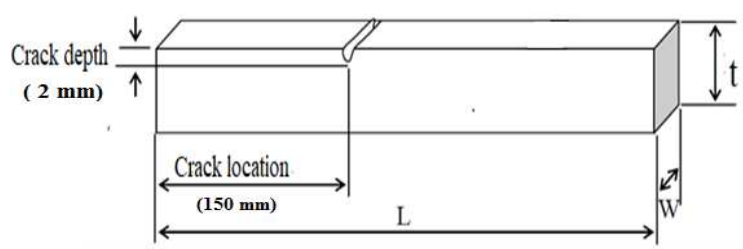

Fig. 2.Line diagram of cracked beam

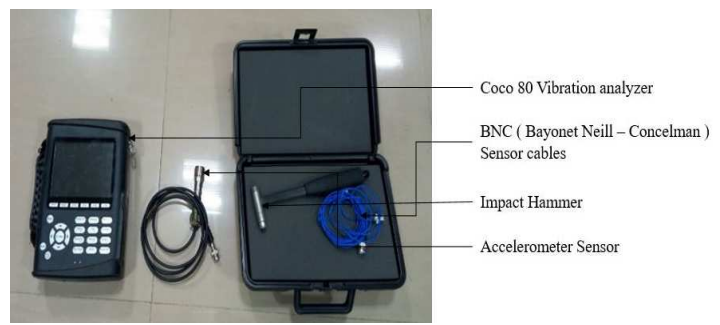

Fig. 3. Image of instruments used for experimental modal analysis 


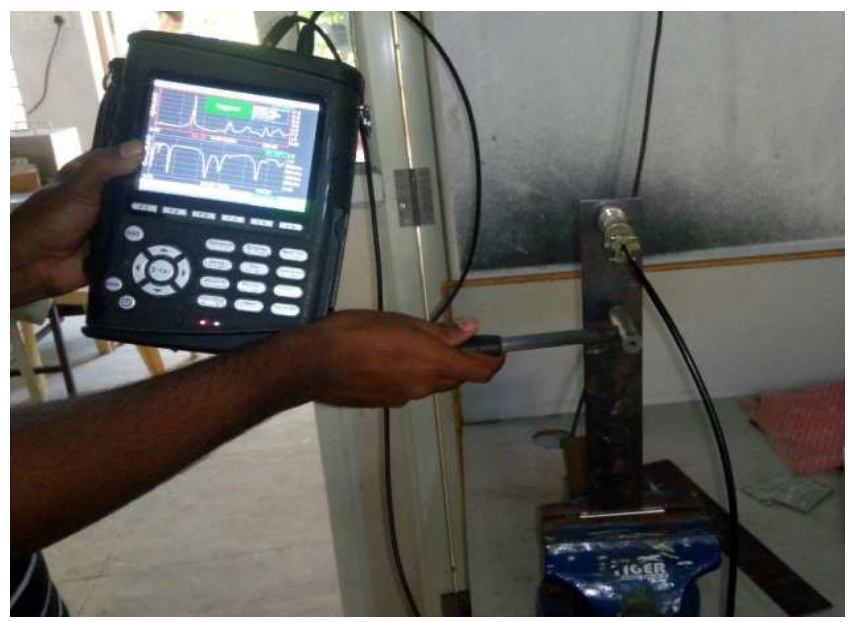

Fig. 4. Image of experimental modal analysis on healthy and cracked beams

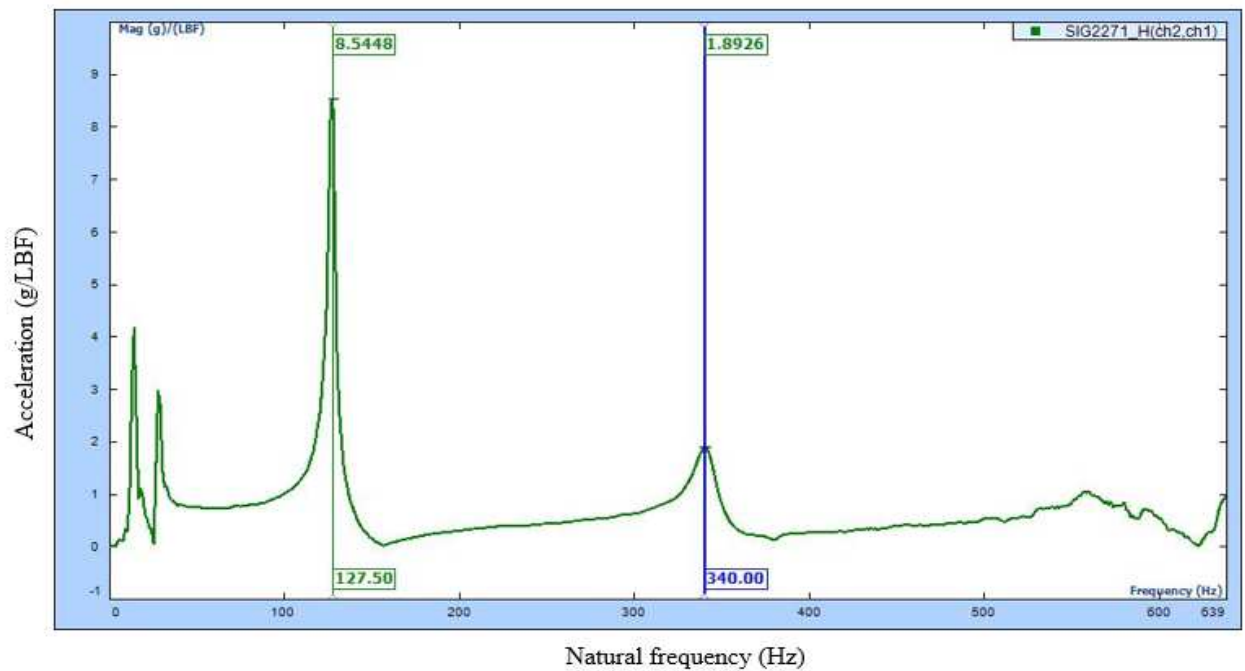

Fig. 5.Frequency response spectrum of healthy beam

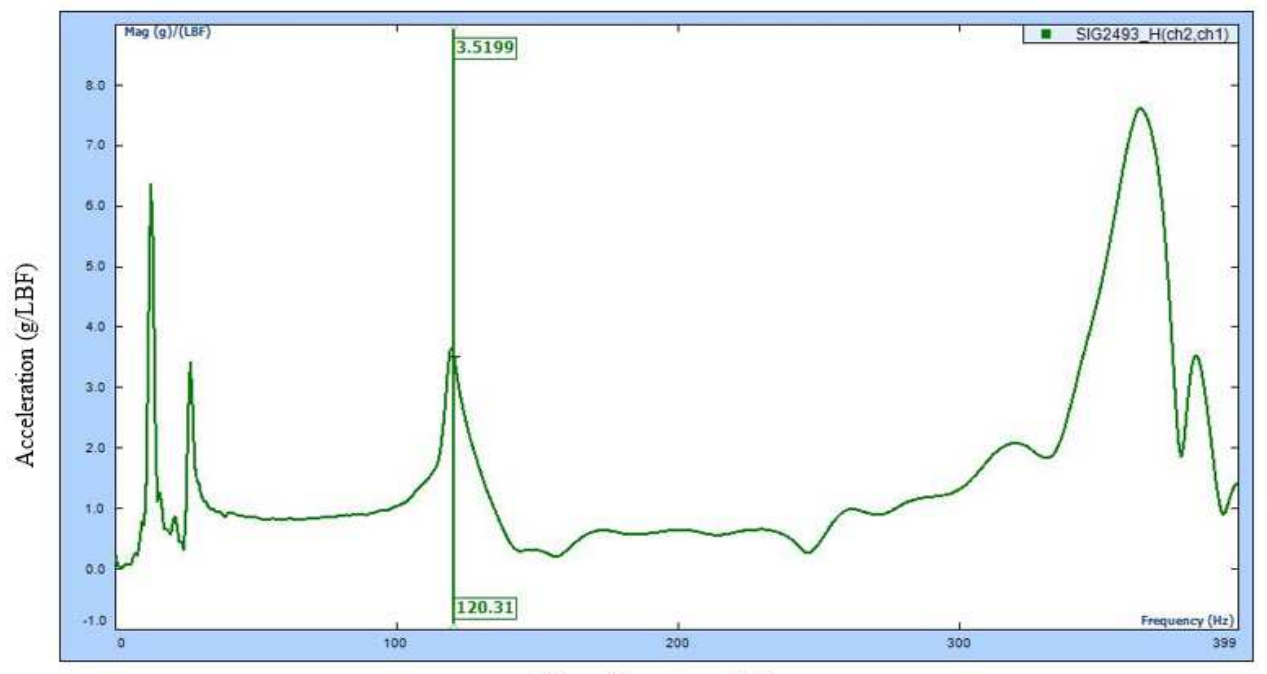

Natural frequency $(\mathrm{Hz})$

Fig. 6.Frequency response spectrum of cracked beam 


\section{FINITE ELEMENT ANALYSIS ON HEALTHY AND CRACKED BEAM}

Modal analysis was performed using finite element software called ANSYS 18.1 to obtain the first three modal frequencies of a healthy and cracked beam. A modal analysis is a tool used to determine the vibration characteristics of the structure. Healthy and cracked beam was modeled using modelling software called CATIA and imported into ANSYS 18.1. Material properties of the structural beam are shown in Table 1. Tetrahedral element (Solid 186) is taken for the generation of mesh for both healthy and cracked beams. Convergence is another important step for prediction of mesh independent results. For this purpose convergence was checked with different element sizes $(12,10,8$ and 6$)$ and plotted the graph between the first mode and element size number. Figure 7 shows the convergence plot between the first mode and element size number. After four iterations close results are observed between mesh sizes 8 and 6 . After convergence, the healthy and cracked beam has meshed with element size number 8 . Figure 8 shows the meshed healthy beam. The first, second and third natural frequencies of healthy beam obtained from the numerical modal analysis are $19.68 \mathrm{~Hz}, 123.26 \mathrm{~Hz}$ and $344.97 \mathrm{~Hz}$ respectively. Figure 9 shows the natural frequencies of the healthy beam. A rectangular open crack beam was modelled using CATIA and imported into ANSYS 18.1 to study the effect of crack on natural frequency. For this purpose, an open transverse crack was made at a distance of $150 \mathrm{~mm}$ from fixed end with crack depth and width of $2 \mathrm{~mm}$ and $1.25 \mathrm{~mm}$ respectively. The fine mesh was created near the crack to capture the variation of modal parameters near the rectangular transverse open crack in the cracked beam. Figure 10 shows the meshed cracked beam. The first, second and third natural frequencies of the cracked beam obtained from numerical modal analysis are $19.49 \mathrm{~Hz}, 120.48 \mathrm{~Hz}$ and $340.98 \mathrm{~Hz}$ respectively. Table 3 shows the numerical modal analysis results of the healthy and cracked beam.

Tab. 3.Numerical modal analysis results of healthy and cracked beam

\begin{tabular}{ccc}
\hline \multirow{2}{*}{ Mode } & \multicolumn{2}{c}{ Natural frequencies [Hz] } \\
\cline { 2 - 3 } & Healthy beam & Cracked beam \\
\hline 1 & 19.68 & 19.49 \\
\hline 2 & 123.26 & 120.98 \\
\hline 3 & 344.97 & 340.98 \\
\hline
\end{tabular}

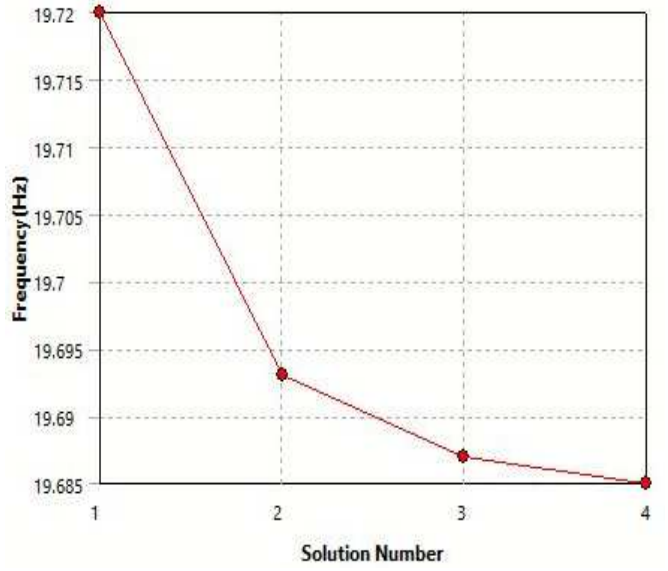

Fig. 7.Mesh convergence plot

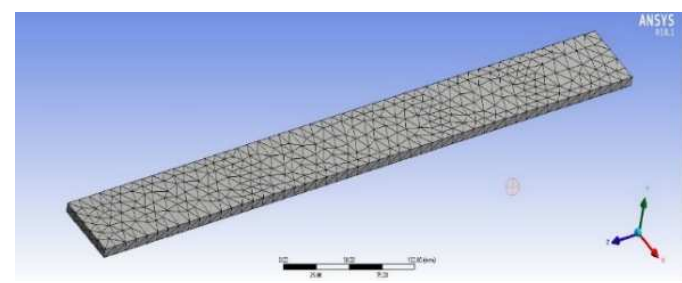

Fig. 8. Meshed healthy beam

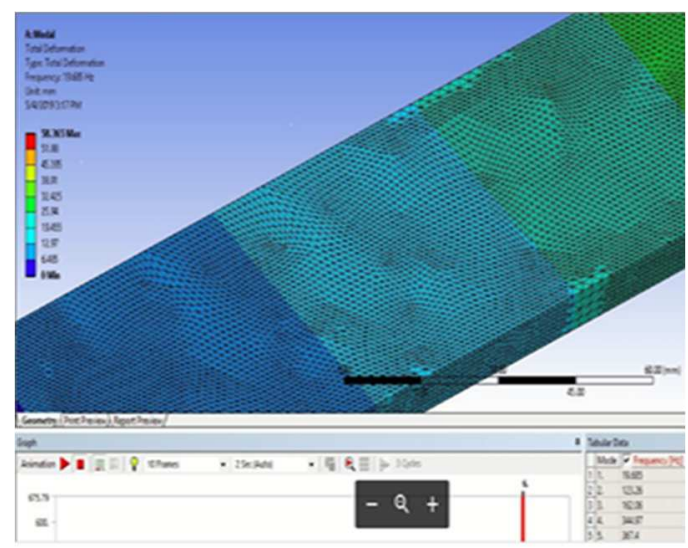

Fig. 9. Natural frequencies of healthy beam

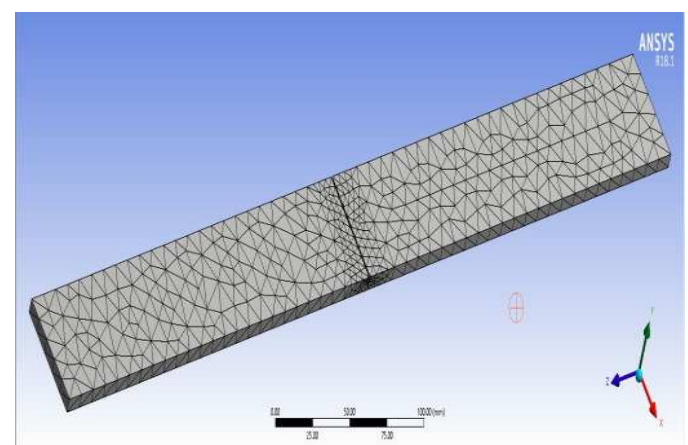

Fig. 10.Meshed cracked beam with rectangular transverse open crack 
Three different parametric studies are carried on a cracked beam using ANSYS 18.1 to know the effect of crack location, crack depth and crack orientation on natural frequencies of the cracked beam. A first parametric study is on analyzing the effect of crack depth on the natural frequencies of the cracked beam, a second parametric study is on analyzing the effect of crack location on the natural frequencies of the cracked beam and third parametric study is on analyzing the effect of crack orientation on the natural frequencies of the cracked beam. Modal analysis is performed on all different geometric models of the cracked beam using ANSYS 18.1 to get the first three natural frequencies.

The first parametric study is to analyze the effect of crack depth on the natural frequencies of the cracked beam. For this purpose, a rectangular crack with $1.25 \mathrm{~mm}$ width is made at a distance of $200 \mathrm{~mm}$ from the fixed end of a cracked beam. Table 4 shows the first three natural frequencies of a cracked beam with various crack depths obtained from ANSYS 18.1 for first parametric study on cracked beam. The maximum first natural frequency was observed at a depth of $0.5 \mathrm{~mm}$ and a minimum first natural frequency is observed at a depth of $3 \mathrm{~mm}$. Figure 11 indicates the effect of crack depth on natural frequency. From Figure 11, it is observed that natural frequency decreases with increasing of crack depth.

The second parametric study is to analyze the effect of crack location on the natural frequencies of the cantilever beam. For this purpose, a rectangular crack with $1.25 \mathrm{~mm}$ width and $2 \mathrm{~mm}$ crack depth is considered. Crack locations of 100, 150, 200, 250, $300,350,400 \mathrm{~mm}$ from the fixed end were considered for second parametric study on cracked beam. A modal analysis is performed on ANSYS 18.1 by varying the crack locations from fixed end of the beam. Table 5 shows first three natural frequencies of a cracked beam with various crack locations obtained from ANSYS 18.1 for second parametric study on cracked beam. From Table 5, it is observed that the effect of crack location is dominant for the first modal frequency as compared to second and third natural frequencies. There is no notable reduction in second and third modal frequencies. Figure 12 shows the effect of crack location on natural frequency. Figure 12 clearly show that natural frequency decreases with increasing crack length.

A third parametric study is to analyze the effect of crack orientation on the natural frequencies of the cantilever beam. Third parametric study is carried out on a rectangular crack with $1.25 \mathrm{~mm}$ width and $2 \mathrm{~mm}$ crack depth on beam. Figure 13 shows the cracked beam with the crack orientation at an angle of $40^{\circ}$ with transverse axis. Table 6 shows the first natural frequency of a cracked beam with different crack orientations obtained from ANSYS 18.1 for third parametric study on a cracked beam. The maximum first natural frequency is observed at crack orientation at an angle of $40^{\circ}$ with transverse axis. Figure 14 indicates the effect of crack orientation on first natural frequency. From Figure 14, it is observed that natural frequency increases with increasing of crack orientation with a transverse axis. From Table 2 and Table 3, it was observed that first natural frequency has more effect on change in crack location and crack depth when compared to second and third natural frequency.

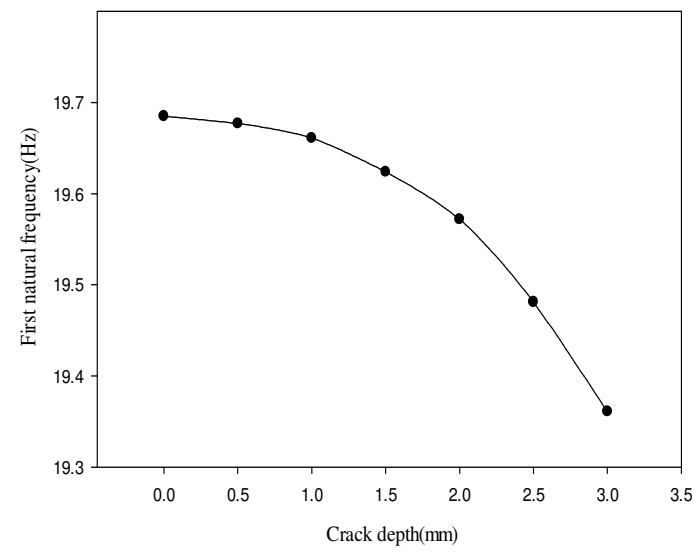

Fig. 11.Effect of crack depth on natural frequency

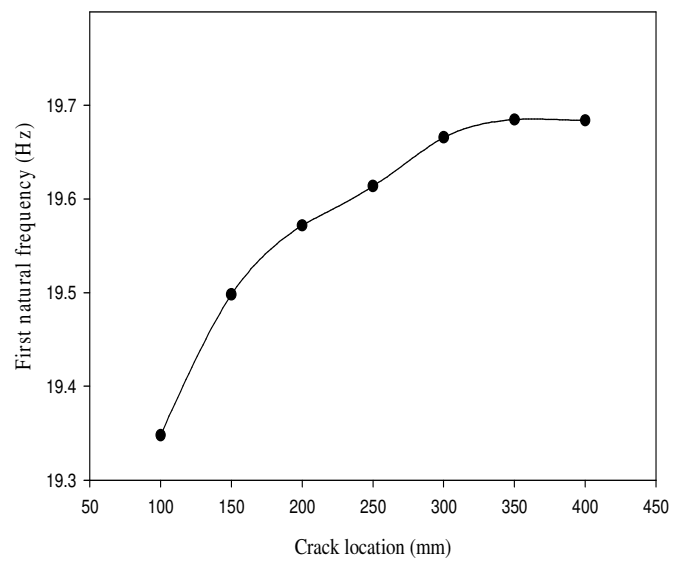

Fig. 12.Effect of crack location on natural frequency

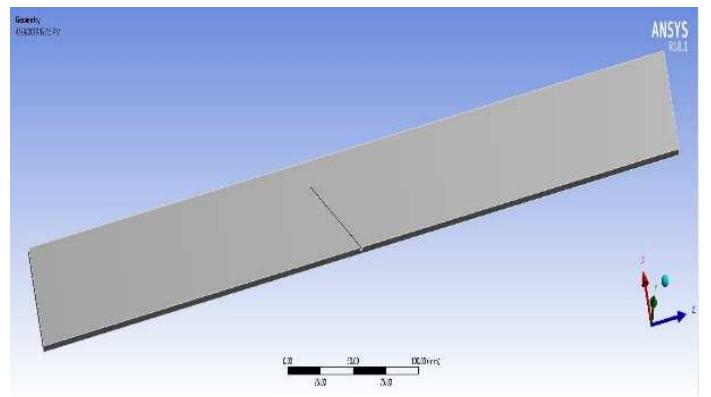

Fig. 13.Cracked beam with crack orientation at an angle of $40^{\circ}$ with transverse axis 


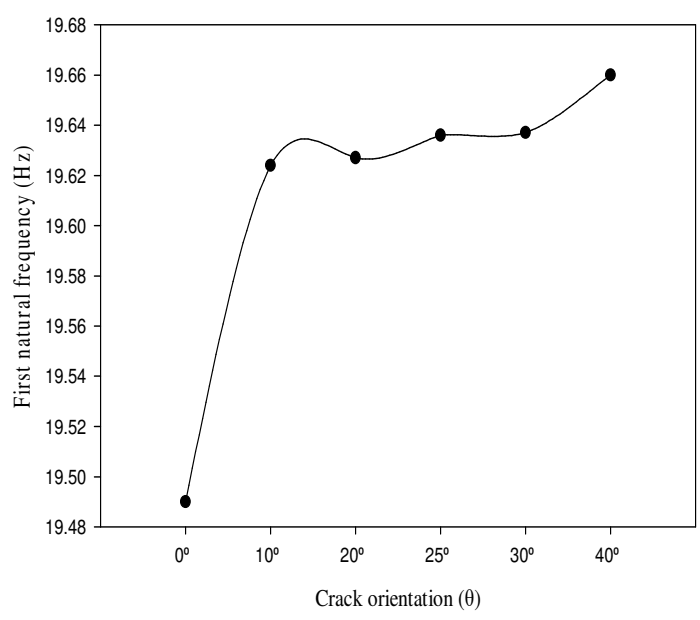

Fig. 14.Effect of crack orientation on natural frequency

Tab. 4.First three natural frequencies of a cracked beam with various crack depths

\begin{tabular}{lc}
\hline Crack orientation $(\theta)$ & $\begin{array}{c}\text { First natural frequency } \\
{[\mathrm{Hz}]}\end{array}$ \\
\hline No crack & 19.685 \\
\hline $0^{\circ}$ & 19.490 \\
\hline $10^{\circ}$ & 19.624 \\
\hline $20^{\circ}$ & 19.627 \\
\hline $25^{\circ}$ & 19.636 \\
\hline $30^{\circ}$ & 19.637 \\
\hline $40^{\circ}$ & 19.660 \\
\hline
\end{tabular}

Tab. 5.First three natural frequencies of a cracked beam with various crack locations

\begin{tabular}{cccc}
\hline $\begin{array}{c}\text { Crack } \\
\text { depth } \\
{[\mathrm{mm}]}\end{array}$ & $\begin{array}{c}\text { First } \\
\text { natural } \\
\text { frequency } \\
{[\mathrm{Hz}]}\end{array}$ & $\begin{array}{c}\text { Second } \\
\text { natural } \\
\text { frequency } \\
{[\mathrm{Hz}]}\end{array}$ & $\begin{array}{c}\text { Third } \\
\text { natural } \\
\text { frequency } \\
{[\mathrm{Hz}]}\end{array}$ \\
\hline No crack & 19.685 & 123.26 & 344.97 \\
\hline 0.5 & 19.677 & 123.18 & 344.84 \\
\hline 1 & 19.661 & 123.02 & 344.59 \\
\hline 1.5 & 19.624 & 122.66 & 343.94 \\
\hline 2 & 19.572 & 122.17 & 343.07 \\
\hline 2.5 & 19.481 & 121.3 & 341.53 \\
\hline 3 & 19.361 & 120.19 & 339.61 \\
\hline
\end{tabular}

\section{RESULTS AND DISCUSSION}

Finite element analysis results are compared with experimental modal analysis results for validation of numerical methodology used in the present paper using finite element software called ANSYS 18.1.
It was observed that the error between the numerical modal analysis and experimental modal analysis results for healthy beam are $1.46 \%$ to $2.79 \%$ and cracked beam are $0.16 \%$ to $1.47 \%$. The results confirmed that there is a good correlation between the numerical and experimental modal analysis results. Now the same numerical results are used for crack identification and estimation of crack location, crack severity and residual life of cracked beam. Table 7 and Table 8 shows the comparison of numerical and experimental modal analysis results for healthy and cracked beam respectively.

Tab. 6.First natural frequency of a cracked beam with different crack orientations

\begin{tabular}{cccc}
\hline $\begin{array}{c}\text { Crack } \\
\text { location } \\
{[\mathrm{mm}]}\end{array}$ & $\begin{array}{c}\text { First } \\
\text { natural } \\
\text { frequency } \\
{[\mathrm{Hz}]}\end{array}$ & $\begin{array}{c}\text { Second } \\
\text { natural } \\
\text { frequency } \\
{[\mathrm{Hz}]}\end{array}$ & $\begin{array}{c}\text { Third } \\
\text { natural } \\
\text { frequency } \\
{[\mathrm{Hz}]}\end{array}$ \\
\hline No crack & 19.685 & 123.26 & 344.97 \\
\hline 100 & 19.348 & 123.27 & 343.46 \\
\hline 150 & 19.498 & 122.98 & 340.98 \\
\hline 200 & 19.572 & 122.17 & 343.07 \\
\hline 250 & 19.614 & 121.35 & 344.97 \\
\hline 300 & 19.666 & 121.64 & 342.41 \\
\hline 350 & 19.684 & 122.29 & 339.50 \\
\hline 400 & 19.685 & 122.95 & 341.23 \\
\hline
\end{tabular}

Tab. 7.Comparison of experimental and numerical modal analysis results of healthy beam

\begin{tabular}{cccc}
\hline \multirow{2}{*}{ Mode } & \multicolumn{2}{c}{ Natural frequency [Hz] } & Percentage \\
\cline { 2 - 4 } & $\begin{array}{c}\text { Experimental } \\
\text { modal analysis }\end{array}$ & $\begin{array}{c}\text { Numerical } \\
\text { modal analysis }\end{array}$ & of error \\
\hline 1 & 20.25 & 19.685 & 2.79 \\
\hline 2 & 127.5 & 123.26 & 3.32 \\
\hline 3 & 340.0 & 344.97 & 1.46 \\
\hline
\end{tabular}

\subsection{Identification of damage present in the beam structure}

An experimental modal analysis was performed on both healthy and cracked beam to detect the presence of the damage in a beam structure [13, 18]. A fast Fourier transformer based vibration analyzer was used to study the modal properties of a healthy and cracked beam. A transverse crack is made at a distance of 150 $\mathrm{mm}$ from the fixed end of the beam; the width and depth of the crack are $1.25 \mathrm{~mm}, 2 \mathrm{~mm}$ respectively. Modal frequencies of both damaged and healthy beam are compared for identification of damage present in the beam structure. From Table 7 and Table 8, it is evident that the natural frequencies of a healthy beam and cracked beam are different. By comparison of 
natural frequencies of both healthy and cracked beam, it observed that the first three natural frequencies of cracked beam are lower than the healthy beam. The change of natural frequencies in the cracked beam confirms that the damage present in the beam structure. The stiffness of the cracked beam always lowers than the healthy beam. So the natural frequencies of the cracked beam are lower than the healthy beam. From table 8 , it was observed that the presence of damage reduces the natural frequencies of the structure. The 3D plot was drawn between crack location, crack depth, and first mode natural frequency using the data taken from Table 4 and Table 5. Figure 15 shows the plot between crack location, crack depth, and first natural frequency. From Figure 15 it was evident that the natural frequencies are changing with the change of crack location and intensity. So the first three natural frequencies can be used to find the crack location and crack severity.

Tab. 8.Comparison of experimental and numerical modal analysis results of cracked beam

\begin{tabular}{llll}
\hline & \multicolumn{2}{c}{ Natural frequency $[\mathrm{Hz}]$} & \\
\cline { 2 - 4 } & $\begin{array}{c}\text { Moderimental } \\
\text { modal analysis }\end{array}$ & $\begin{array}{c}\text { Numerical } \\
\text { modal } \\
\text { analysis }\end{array}$ & $\begin{array}{c}\text { Percentage of } \\
\text { error }\end{array}$ \\
\hline 1 & 19.53 & 19.498 & 0.16 \\
\hline 2 & 120.31 & 120.98 & 0.55 \\
\hline 3 & 336.03 & 340.98 & 1.47 \\
\hline
\end{tabular}

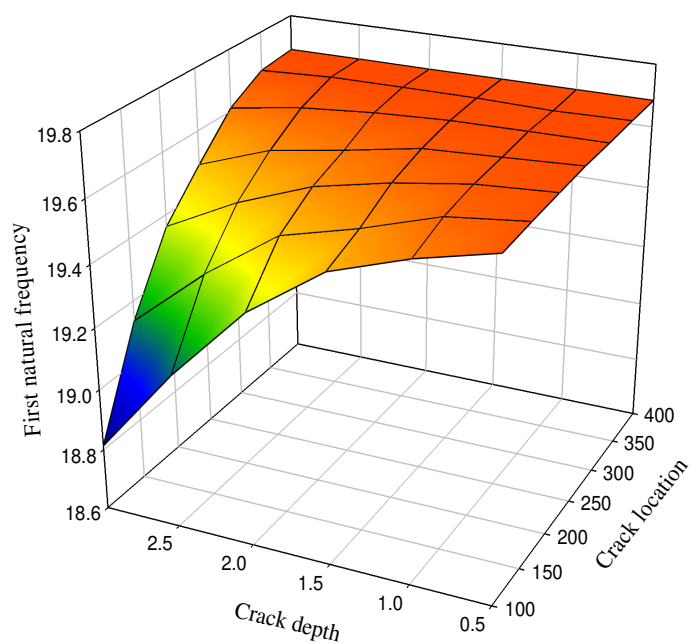

Fig. 15.3D plot between crack location, crack depth, and first natural frequency

\subsection{Estimating geometric location of the crack present in the beam structure}

Geometric location of the crack present in the beam structure was estimated using the contour plots of normalized first three natural frequencies of healthy and cracked beam. A transverse crack has width and depth of $1.25 \mathrm{~mm}$ and $2 \mathrm{~mm}$ respectively was made at a distance of $150 \mathrm{~mm}$ from the fixed end of the beam for estimating the geometric location of the crack. A separate contour plots are made for normalized first, second and third natural frequencies of healthy and cracked beam with the help of Minitab 18 software. A contour plot is a graph between crack depth and crack location for a particular modal frequency. For all contour plots, crack location is taken on the $\mathrm{X}$-axis and crack depth is taken on the Y-axis. Normalized natural frequencies are calculated using Equation-1. Figure 16, Figure 17 and Figure 18 shows the contour plots for normalized first, second and third natural frequencies respectively. As the each natural frequency is unique for a particular crack location and crack depth, the common point of intersection of three contour lines of Figure 16, Figure 17 and Figure 18 indicates the geometric location of the crack. Figure 19 shows the geometric location of the crack present in the cracked beam. This common point of intersection is unique due to fact that each normalized natural frequency of a cracked beam can be represented by a mathematical equation that is depends on crack location and crack depth. Table 9 indicates comparison of actual and estimated geometric location of crack present in the cracked beam using ANSYS 18.1. The error between the actual and estimated geometric location of crack present in the cracked beam is $0.17 \%$ to $0.3 \%$ only. From the results shown in Table 9, it is confirmed that contour plots of normalized first three natural frequencies of healthy and cracked beam can be used for estimation of crack location in the cracked beam with reasonable degree of accuracy.

$$
f_{N}=\frac{\text { Modalfrequencyof damagedbeam }}{\text { Modalfrequencyof healthybeam }} .
$$

Tab. 9.Comparison of actual and estimated geometric locations of crack present in the cracked beam

\begin{tabular}{lccc}
\hline Parameter & $\begin{array}{c}\text { Actual } \\
\text { geometric } \\
\text { location } \\
\text { of crack }\end{array}$ & $\begin{array}{l}\text { Estimated } \\
\text { geometric } \\
\text { location of } \\
\text { crack using } \\
\text { ANSYS 18.1 }\end{array}$ & $\begin{array}{c}\text { Percentage } \\
\text { of error }\end{array}$ \\
\hline $\begin{array}{l}\text { Crack } \\
\text { location } \\
\text { [mm] }\end{array}$ & 150 & 149.55 & 0.3 \\
\hline $\begin{array}{l}\text { Crack } \\
\text { depth } \\
{[\mathrm{mm}]}\end{array}$ & 2 & 2.00357 & 0.17 \\
\hline
\end{tabular}


Contour line of first natural frequency vs Crack depth, Crack location

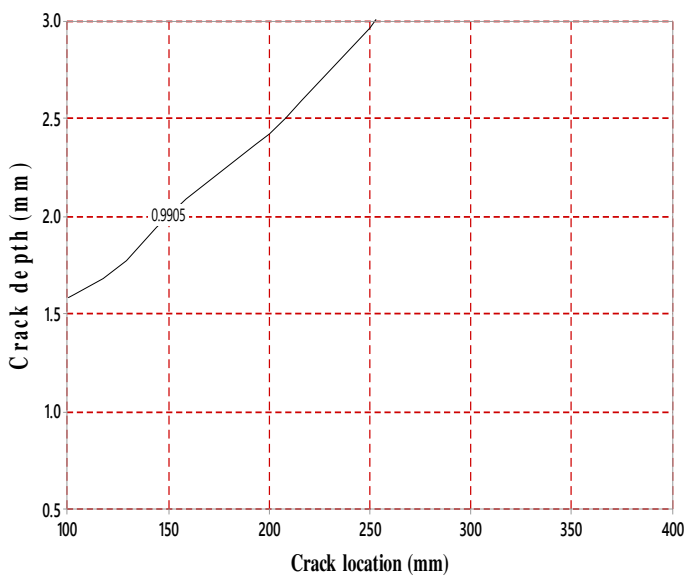

Fig. 16.Contour plot for normalized first natural frequency

Contour line of second natural fre quency vs Crack depth, Crack location

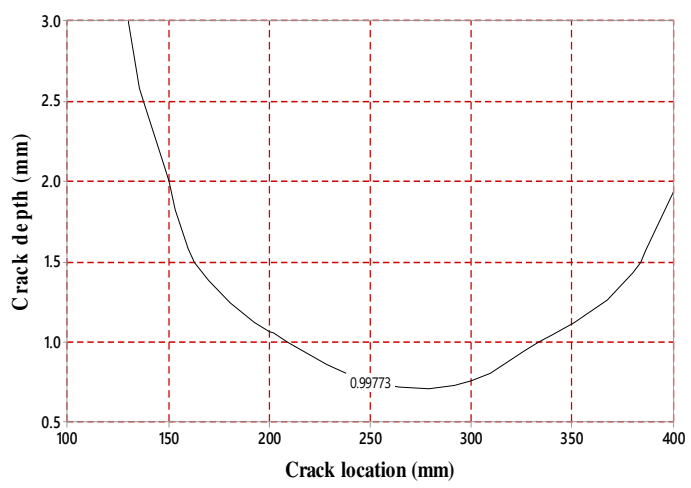

Fig. 17.Contour plot for normalized second natural frequency

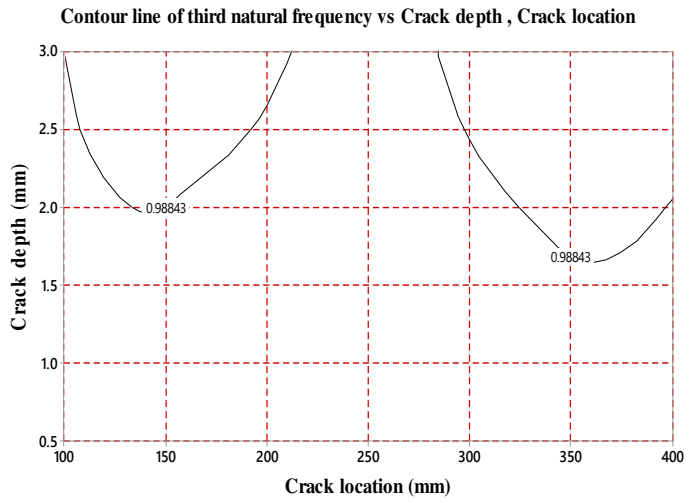

Fig. 18.Contour plot for normalized third natural frequency

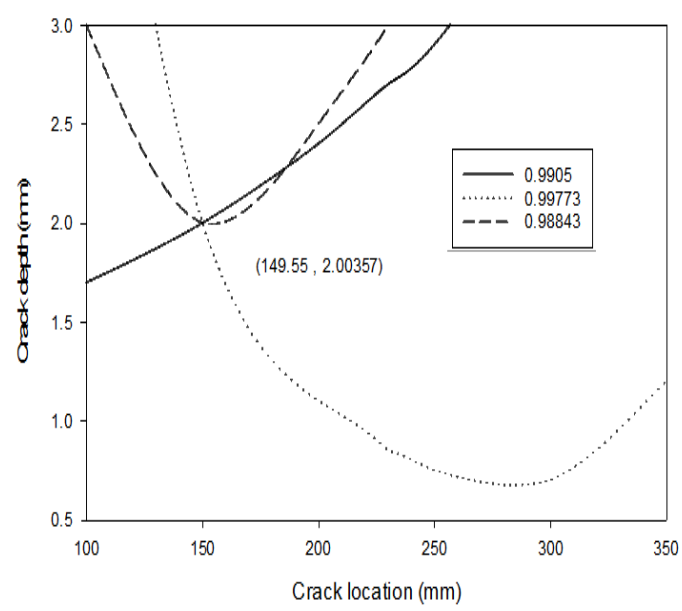

Fig. 19.Geometric location of crack present in the cracked beam

\subsection{Quantifying the severity of the damage present in beam structure}

Dimarogonas and Paipetis equation [3] was used to quantifying the severity of the damage present in beam structure. Severity of the damage present in beam structure can be quantified as a change in the stiffness of a cross section. Dimarogonas and Paipetis developed a relation to find the stiffness ( $\left.K^{\prime}\right)$ in the vicinity of the cracked section of a cantilever beam. According to Dimarogonas and Paipetis equation, damage becomes more severe when dimensionless local flexibility coefficient $\left(C_{f}\right)$ is nearer to unity. A transverse crack has width of $1.25 \mathrm{~mm}$ and various depths of $0.5,1,1.5,2,2.5,3$ and $4 \mathrm{~mm}$ was made at a distance of $150 \mathrm{~mm}$ from the fixed end of the beam for the quantifying the severity of the damage present in beam structure. Table 10 indicates the crack local stiffness and flexibility coefficients for cracked beam with various damage intensities as crack depth changes from $0.5 \mathrm{~mm}$ to $4 \mathrm{~mm}$. From the results it is observed that minimum severity of damage was observed at crack depth of $0.5 \mathrm{~mm}$ and maximum severity of damage was observed at crack depth of 4 $\mathrm{mm}$. From the results it is confirmed that Dimarogonas and Paipetis relation can be successfully used for quantifying the severity of the damage present in beam structure. Dimarogonas and Paipetis relation used to estimate the severity of the damage is shown in Equation 2.

$$
\begin{gathered}
C_{f}=\left(\frac{K \times L}{E \times I}\right), \\
K=\frac{1}{C} \\
C=\left(\frac{5.346 \times t}{E \times I}\right) f\left(\frac{d}{t}\right),
\end{gathered}
$$


where, $K$ - stiffness of the beam, $C$ - compliance, $E$ -Young's modulus of the material, $t$ - beam thickness, $d$ - crack depth, $I-$ moment of inertia of the beam cross-section.

$$
\begin{aligned}
& f\left(\frac{d}{t}\right)=1.8624\left(\frac{d}{t}\right)^{2}-3.95\left(\frac{d}{t}\right)^{3}+16.375\left(\frac{d}{t}\right)^{4}-37.226\left(\frac{d}{t}\right)^{5} \\
& +76.81\left(\frac{d}{t}\right)^{6}-1269\left(\frac{d}{t}\right)^{7}+172\left(\frac{d}{t}\right)^{8}-14387\left(\frac{d}{t}\right)^{9}+66.56\left(\frac{d}{t}\right)^{10}
\end{aligned}
$$

Tab. 10.Local stiffness and flexibility coefficient for cracked beam

\begin{tabular}{lll}
\hline $\begin{array}{l}\text { Crack depth } \\
{[\mathrm{mm}]}\end{array}$ & $\begin{array}{l}\text { Local stiffness } \\
{[\mathrm{N} / \mathrm{mm}]}\end{array}$ & $\begin{array}{l}\text { Local flexibility } \\
\text { coefficient }\end{array}$ \\
\hline 0.5 & $496,608,166.2$ & 1379 \\
\hline 1 & $131,729,396.2$ & 365.914 \\
\hline 1.5 & $58,822,560.57$ & 163.39 \\
\hline 2 & $31,704,363.15$ & 88.06 \\
\hline 2.5 & $18,631,050.06$ & 51.7529 \\
\hline 3 & $11,300,185.82$ & 31.38 \\
\hline 4 & $3,927,267.323$ & 10.9 \\
\hline
\end{tabular}

\subsection{Validation of estimation of residual life of healthy beam}

The residual life of the healthy beam obtained from numerical analysis was validated with the experimental results for validation of numerical methodology used for estimation of residual life of cracked beam. For this purpose, an experimental setup was fabricated for a healthy beam using strain gauges arranged in Wheatstone bridge circuit for measurement of a strain. Figure 20 shows the image of strain measurement for the healthy beam. A point load of $98.06 \mathrm{~N}$ is applied on one end of the beam and corresponding strain was taken from digital display connected to Wheatstone bridge circuit. Strain measured from the strain gauge experimental setup is $0.00083845 \mathrm{~mm} / \mathrm{mm}$ for a load of $98.06 \mathrm{~N}$. The same value of strain is used for calculation stress using Young's modulus of $200 \mathrm{GPa}$. The corresponding stress is $167.9 \mathrm{MPa}$ for strain of $0.00083845 \mathrm{~mm} / \mathrm{mm}$. The value of stress obtained from strain gauge experiment is used for validation of stress obtained from numerical analysis using ANSYS 18.1 for healthy beam. Figure 21 shows the strain generated in the healthy beam. The estimated strain for healthy beam from numerical analysis is $0.00083109 \mathrm{~mm} / \mathrm{mm}$ and corresponding stress is $166.22 \mathrm{MPa}$. Table 11 shows the comparison of experimental and numerical stress results of healthy beam obtained from strain gauge experiment and numerical analysis using ANSYS 18.1. From the results it was observed that, the error between experimental and numerical stress results is only $1 \%$. So there is good conformity observed between the experimental and numerical results. Basquin equation gives the relationship between applied stress cycles $\left(\sigma_{s}\right)$ and number of life cycles to failure $\left(N_{f}\right)$. According to this theory, failure occurs in a structure due to reversed bending stress. The residual life of healthy beam is calculated using Equation 5. The estimated residual life for healthy beam using Equation-3 is $4.5462 \times 10^{7}$ cycles. The same numerical methodology and Basquin's equation is used to estimate the residual life of a cracked beam with reasonable degree of accuracy.

$$
N_{f}=\left(\frac{\sigma_{s}}{a}\right)^{\frac{1}{b}},
$$

where, $\mathrm{a}$ and $\mathrm{b}$ are material constants depends on ultimate tensile strength $\left(\sigma_{u}\right)$ and endurance strength $\left(\sigma_{e}\right)$.

$$
\begin{gathered}
a=\frac{\sigma_{e}}{10^{6 b}}, \\
b=\frac{1}{3}\left(\left(\log \left(\sigma_{e}\right)-\log \left(0.9 \times \sigma_{u}\right)\right) .\right.
\end{gathered}
$$

\begin{tabular}{|c|c|c|}
\hline \multicolumn{2}{|c|}{ Applied stress [MPa] } & \multirow{2}{*}{$\begin{array}{c}\text { Percentage of error } \\
\text { between } \\
\text { Experimental and } \\
\text { Numerical method }\end{array}$} \\
\hline $\begin{array}{c}\text { Strain gauge } \\
\text { experiment } \\
\text { method }\end{array}$ & $\begin{array}{l}\text { Numerical method } \\
\text { (ANSYS18.1) }\end{array}$ & \\
\hline 167.9 & 166.22 & 1.0 \\
\hline
\end{tabular}

Tab. 11.Comparison of experimental and numerical stress results for healthy beam

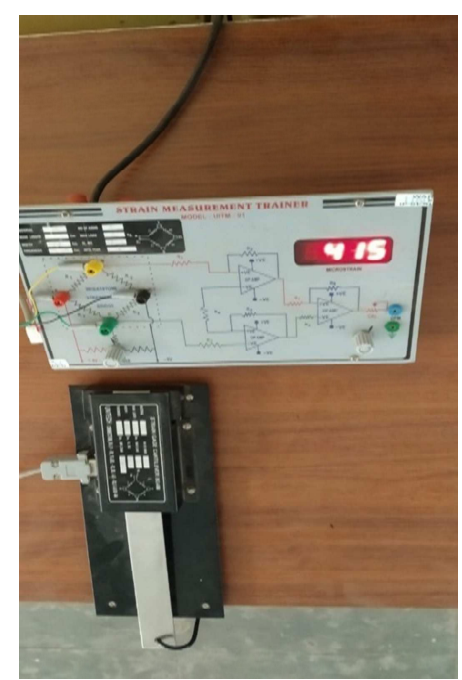

Fig. 20.Image of strain measurement for healthy beam

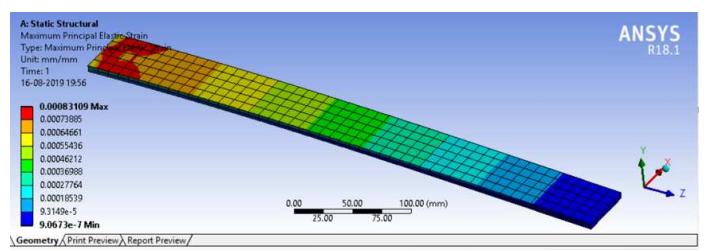

Fig. 21.Strain of healthy beam 


\subsection{Residual life estimation of cracked beam}

A finite analysis was performed on cracked beam using ANSYS 18.1 to for estimation of residual life of cracked beam [1, 16, 17]. A transverse crack has width of $1.25 \mathrm{~mm}$ and depth of $2 \mathrm{~mm}$ was made at a distance of $150 \mathrm{~mm}$ from the fixed end of the beam for estimation of residual life of cracked beam. A point load of $98.06 \mathrm{~N}$ is applied on one end of the beam and the other end of the beam is fixed. Tetrahedral mesh with solid 186 element was generated for cracked beam. Convergence analysis was carried out for different element sizes and finally convergence obtained with an element size of $8 \mathrm{~mm}$ for cracked beam. The maximum stress cycles $\left(\sigma_{s}\right)$ obtained from ANSYS 18.1 is used to find the residual life cracked beam. Figure 22 shows the strain generated in the cracked beam. The estimated strain for cracked beam from the numerical analysis is $0.0013831 \mathrm{~mm} / \mathrm{mm}$ and corresponding stress is $276.62 \mathrm{MPa}$. This stress result is used for estimation of residual life of cracked beam using Equation-3. The residual life for cracked beam estimated from Equation-3 is $1.14284 \times 10^{5}$ cycles and for the healthy beam is $4.5462 \times 10^{7}$ cycles. From the results, it was observed that the residual life of the healthy beam has more than $10^{6}$ cycles, so a healthy beam has infinite life. The residual life of a cracked beam has less than $10^{6}$ cycles. From the results, it was observed that the residual life of a cracked beam is less than the healthy beam and confirmed that the presence of crack declines the residual life of the cracked beam.

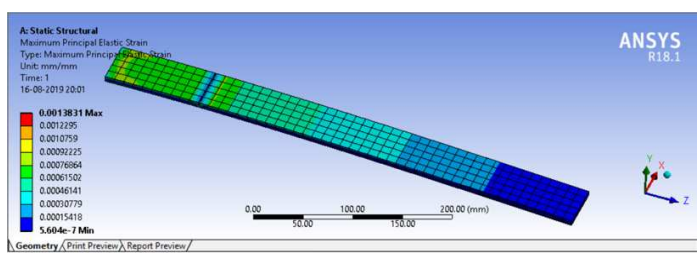

Fig. 22.Strain of cracked beam

\section{CONCLUSIONS}

The first three natural frequencies of a healthy and cracked beam were calculated through numerical and experimental modal analysis methods. The error between numerical and experimental modal analysis results are only $0.16 \%$ to $2.79 \%$. Form the results, it was concluded that there is good conformity observed between numerical and experimental modal analysis results. Three different parametric studies are carried out on cracked beam using ANSYS 18.1 to know the effect of crack location, crack depth and crack orientation on the first three natural frequencies of the cracked beam. From parametric studies, it was concluded that natural frequency decreases with increasing of crack depth and crack length and also it was found that natural frequency increases with increasing of crack orientation with a transverse axis.
Damage present in the beam structure was identified by experimental modal analysis method. Geometric location of crack was estimated with an error of $1 \%$ using normalized first three natural frequencies of the healthy and cracked beam. The Severity of the damage present in beam structure was quantified using Dimarogonas and Paipetis equation. Form these results it was concluded that minimum severity was observed at a crack depth of $0.5 \mathrm{~mm}$ and maximum severity was observed at a crack depth of $4 \mathrm{~mm}$. Basquins equation and numerical modal analysis were used to estimate the residual life of a cracked beam. Form the results, it was found that the residual life of cracked beam is $1.14284 \times 10^{5}$ cycles.

\section{Nomenclature}

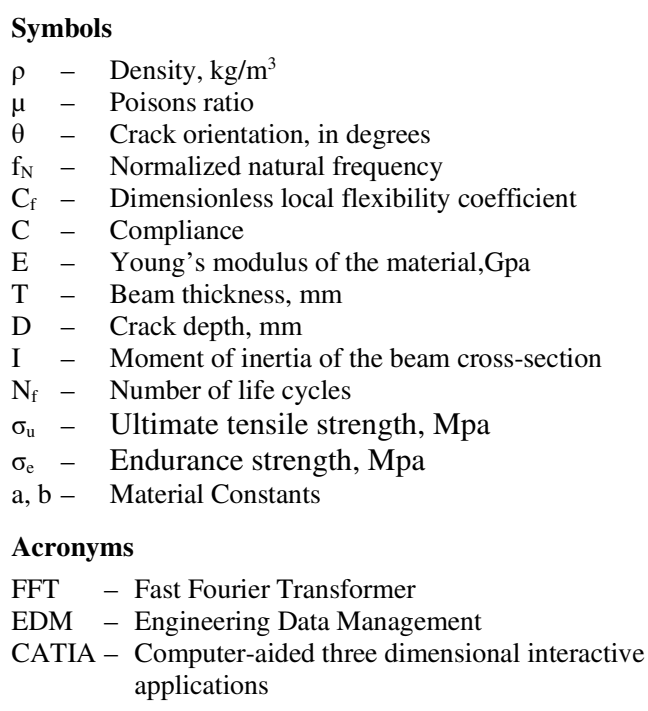

\section{References}

1. Adarsh A. (2015). Fatigue behavior and life predictions of forged steel and powder metal connecting rods. International Journal on Emerging Technologies, Vol. 6, No. 1, pp. 56-60

2. A. Rytter. (1993). Vibration Based Inspection of Civil Engineering Structures. Ph. D. dissertation. Department of Building Technology and Structural Engineering, Aalborg University, Denmark,. pp. 193

3. Dimarogonas A.D., Paipetis S.A. (1983). Analytical methods in rotor dynamics, Springer, Netherlands

4. Zizheng S., Xiaoying Z., Yiming Z. (2019). Cracking elements method for simulating complex crack growth. J. Appl. Comput. Mech. Vol. 5, No. 3, pp. 552-562

5. Elshamy M., Crosby W.A., Elhadary M. (2018). Crack detection of cantilever beam by natural frequency tracking using experimental and finite element analysis. Alexandria Engineering Journal, Vol. 57, No. 4, pp. 3755-3766

6. Walunj P.S., Chouguleb V.N., Anirban C. M. (2015). Investigation on modal parameters of rectangular cantilever beam using experimental modal analysis. Materials Today: Proceedings, Vol .2, No. 4, pp. 21212130

7. Khalkar V., Ramachandran S. (2017). Paradigm for natural frequency of an un-cracked cantilever beam and 
its application to cracked beam. ARPN Journal of Engineering and Applied Sciences, Vol. 12, No. 6, pp. 1714-1729

8. Kumar P., Bhaduri S., Kumar A. (2016). Vibration analysis of cantilever beam: an experimental study. International Journal for Research in Applied Science \& Engineering Technology, Vol. 4, No. 2, pp. 361-369

9. Pragnesh K., Dipal Patel., Vipul Patel A. (2014). Theoretical and software based comparison of cantilever beam: modal analysis. International Journal of Innovative Research in Advanced Engineering, Vol. 1,No. 5, pp. 75-79

10. Chaphalkar S. P., Subhash N. K., Arun M. M. (2015). Modal analysis of cantilever beam structure using finite element analysis and experimental analysis. American Journal of Engineering Research, Vol. 4, No. 10, pp. $178-185$

11. Sadettin O. (2007). Analysis of free and forced vibration of a cracked cantilever beam. NDT E Int., Vol. 40, No. 6, pp. $443-450$

12. Nikil J. P. (2014). Vibrational analysis of portable crane International Journal of Engineering Research and Technology, Vol. 3, No. 5, pp. 471-473

13. Mirko S. M., Ivana V. V., Katarina S. M., Natasa, T., Stevan M. M. (2018). Residual life estimation of cracked aircraft structural components. FME Transactions, Vol. 46, No. 1, pp. $124-128$

14. leonard F., Lanteigne J., Lalonde S. (2001). Free vibration behaviors of a cracked cantilever beam and crack detection. Mechanical Systems and Signal Processing, Vo1. 5, No. 3, pp. 529-548

15. Nahvi H., Jabbari M. (2005). Crack detection in beams using experimental modal data and finite element model. Int. J. Mech. Sci., Vol. 47 , No. 10, pp. 1477-1497

16. Jiankong. (2014). Crane residual life estimation method based on artificial neural networks. BioTechnology: An Indian Journal, Vol. 10, No. 11, pp. 5674-5681

17. Hajializadeh D., OBrien E. J., Conno A. J. O. (2017) Virtual structural health monitoring and remaining life prediction of steel bridges. Canadian Journal of Civil Engineering, Vol. 44, No. 4, pp. 264-273

18. Aiko F., Junji K. (2004). Identification of structural damage based on vibration responses. 13th World Conference on Earthquake Engineering, Canada, paper no 134

\section{Biographical notes}

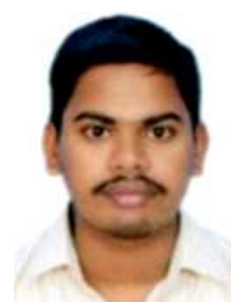

Gandam Anand Siva received his Master of Technology in Mechanical engineering (specialisa-tioncomputer aided analysis and design (CAAD)) from Gayatri Vidya Parishad College of Engineering (Autonomous), in 2019.Currently he works as an assistant professor of department of mechanical engineering in GVP-Satya Institute of Technology and Management (GVP-SITAM). His scientific interests focus on problems concerning vibration monitoring, design optimization and diagnostics of machining processes. He has presented in 2 national conferences. He has published 5 scientific papers in international journals.

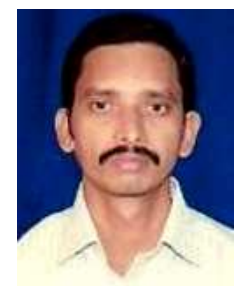

Shinagam Ramakrishna received his $\mathrm{PhD}$ in Mechanical Engineering (specialisation: CFD, acoustics optimization, vibrations, composites, Tribology) from Andhra University in 2010, Master of Technology from J.N.T.U.K., Kakinada in 2005.Since 2011, has been a Researcher for the Department of Mechanical Engineering in Gayatri Vidya Parishad College of Engineering (Autonomous) and, where currently he works as an Associate Professor. His scientific interests are focused on issues related with CFD, Acoustics Optimization, vibrations, composites, Tribology. He successfully completed 3 research projects and 21 consultancy projects. He has published more than 50 scientific papers in various international and national journals. 
